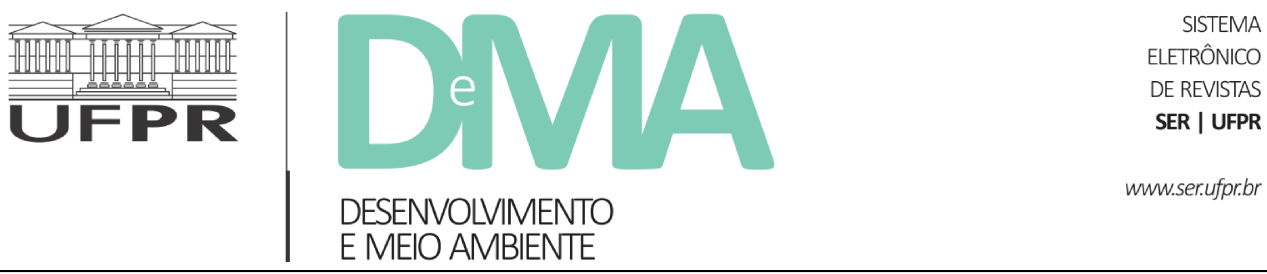

\title{
A agroecologia como um problema público: um olhar a partir da trajetória da Articulação Nacional de Agroecologia
}

\section{Agroecology as a public matter: an overlook through the trajectory of Brazil's National Articulation of Agroecology}

\author{
Ligia Scarpa BENSADON ${ }^{1 *}$ \\ ${ }^{1}$ Instituto Federal de Educação, Ciência e Tecnologia do Rio de Janeiro (IFRJ) - Campus Niterói, RJ, Brasil. \\ *E-mail de contato: ligia.bensadon@ifrj.edu.br
}

Artigo recebido em 30 de janeiro de 2018, versão final aceita em 9 de março de 2019.

\begin{abstract}
RESUMO: A proposta da agroecologia emergiu nas últimas décadas inserida nas alternativas contra-hegemônicas de desenvolvimento, expressando-se de forma ampla como movimento social, ciência, prática e um modo de vida. Diversas organizações de movimentos sociais e Organizações Não Governamentais (ONGs) do campo agroecológico têm interlocuções na Articulação Nacional de Agroecologia (ANA). A pesquisa buscou compreender a formação e organização política da ANA, entendida como uma rede com heterogêneos vínculos e atores sociais, criada em 2002 para promover formulações de políticas e intercâmbios entre organizações que atuam com agroecologia. O fio condutor da pesquisa seguiu a trajetória da ANA para entender de que maneira promoveu a agroecologia enquanto um problema público a ser reconhecido e se expressou como uma rede social, tanto para fazer convergir posicionamentos e ações quanto para se opor ao agronegócio e disputar políticas públicas. $\mathrm{O}$ estudo parte da reconstrução histórica do movimento agroecológico, desde os passos iniciais da agricultura alternativa até a difusão e defesa da agroecologia por atores e setores diversos. Como instrumentos metodológicos, realizamos entrevistas semiestruturadas, além da participação em eventos e análise de documentos diversos, tendo como referencial analítico as noções de redes sociais e movimentos sociais, com uma abordagem relacional. A ação em rede, mesmo no esforço da horizontalidade, expressou concentrações, controvérsias e dinâmicas de envolvimento diversas. O estudo permitiu conhecer as relações e os processos sociais que geraram a formação da ANA, bem como sua forma de ação em rede e sua expressão como parte do movimento agroecológico. A ANA impulsionou o significado político da agroecologia como um frame, mobilizando atores, ações e propostas de uma nova utopia.
\end{abstract}

Palavras-chave: movimentos sociais; frame; problema público. 
ABSTRACT: The proposal of agroecology has emerged in recent decades inserted into non-hegemonic developmental alternatives, expressing itself broadly as a social movement, science, practice, and lifestyle. Several social movement organizations and NGOs of the agro-ecological field congregate in the National Articulation of Agroecology (ANA). This research sought to understand the formation and political organization of the ANA, which is understood as a network with heterogeneous connections and social actors, established in 2002 to promote policy formulation and exchanges between organizations working with agroecology. We followed ANA's trajectory to understand how the association promoted agroecology as a recognized public issue and represented itself as a social network, both for converging approaches and actions, as to oppose the agribusiness and to dispute public policies. The study begins with the historical reconstruction of the agro-ecological movement, from the initial steps of alternative agriculture to the spreading and defense of agroecology by different actors and sectors. As methodological tools, we conducted semi-structured interviews, participated in events and analyzed various documents. The action as a network, even in a horizontal effort, revealed concentrations, controversies and dynamics with different degrees of involvement. The study allowed us to observe the relationships and social processes that led to the formation of the ANA, as well as its form of action as a network and its representation as part of the agro-ecological movement. ANA boosted the political significance of agroecology as a frame, mobilized the actors to a public issue and to network shares with proposals for a new utopia.

Keywords: social movements; frame; public issue.

\section{Introdução}

Neste artigo analisamos o aparecimento e adesão da agroecologia no país, em especial a partir da trajetória da Articulação Nacional de Agroecologia (ANA), criada em 2002 para formular propostas de políticas e promover intercâmbios entre Organizações Não Governamentais (ONGs) e organizações de movimentos sociais ${ }^{1}$ que atuam no campo agroecológico. As aproximações que permitiram uma articulação como essa implicou entender o processo de aparecimento da agroecologia como um problema público (Cefaï, 2002) e a ação coletiva construída, e como essas questões se refletiram na formação e construção do campo agroecológico. As questões que nos orientaram analiticamente ao longo desse estudo foram: como a ANA se construiu como um ator coletivo e uma rede? Nessa caminhada, como trouxe a agroecologia enquanto um problema público e um frame ${ }^{2}$ ? (Bensadon, 2016).

O presente artigo é fruto da pesquisa de mestrado defendida em 2016 no Programa de Pós-Graduação de Ciências Sociais em Desenvolvimento, Agricultura e Sociedade da Universidade Federal Rural do Rio de Janeiro (CPDA/UFRRJ), sob a orientação da professora Leonilde Servolo de Medeiros. Para tal, obtivemos acesso a dados primários, como a realização de entrevistas semiestruturadas entre 2014 e 2016 com diversas lideranças nacionais envolvidas com o movimento agroecológico, análise de diversos documentos da ANA(encontros nacionais e reuniões) e participação em alguns eventos nacionais, como

\footnotetext{
${ }^{1} \mathrm{O}$ termo organizações de movimentos sociais é utilizado pelas análises das oportunidades políticas, como em Tarrow (2009). Usamos essa expressão para diferenciar a análise de organizações da análise teórica dos movimentos sociais.

${ }^{2}$ Para a pesquisa utilizamos o termo frame em inglês devido à limitação na tradução do seu sentido para o português, como a noção pouco flexível de enquadramento. Dentre os autores que utilizam essa abordagem, citamos Snow \& Byrd (2010), Tarrow (2009), Cefaï (2002) e Cefaï \& Trom (2008).
} 
reuniões e encontros. Com esse acesso, o objetivo foi identificar os atores presentes, as pautas principais, a forma de ação e os entendimentos consensuados, a partir de uma descrição densa (Geertz, 1989) que procurou explicitar e esclarecer os fenômenos e as construções sociais realizadas a partir de uma interpretação $^{3}$.

Além desta introdução, o artigo organiza-se em outros três capítulos, sendo que no próximo são destacadas algumas questões relacionadas à teoria dos movimentos sociais que ancoram a análise, articulando e conceituando ator coletivo, frame e problema público. No capítulo seguinte, detalha-se o processo de construção do movimento agroecológico e da ANA, permeando suas interfaces de convergências e divergências. E ao final são tecidas as considerações finais.

\section{A abordagem a partir da teoria dos movimentos sociais}

O termo movimento social possui uma multiplicidade de significados e foi problematizado por diversas vertentes teóricas, como a teoria de mobilização de recursos (Olson, 1965), oportunidades políticas (Mcadam et al., 2009), novos movimentos sociais (Touraine, 2006), frames (Benford \& Snow, 2000; Cefaï, 2002; Cefaï \& Trom, 2008; Snow \& Byrd, 2010), repertórios de ação coletiva (Tilly, 1978), resistência cotidiana (Thompson, 1998; Scott, 2002), reconhecimento (Honneth, 2003; Fraser, 2007), relação com políticas públicas e democracia (Bourdieu, 1990; Offerlé, 1998) e redes de movimentos sociais
(Della Porta \& Diani, 2006; Scherer-Warren, 2008), dentre outros.

Para este estudo, optamos por uma abordagem metodológica, ou seja, uma lente de análise para as práticas sociais pesquisadas, sem limitar a visão de movimento social ao âmbito organizacional e sem substancializá-lo (Melucci, 2001).

Esta pesquisa dialogou com a análise dos movimentos sociais para entender as heterogeneidades da ANA como um ator coletivo, as energias empreendidas para manter sua unidade em torno da agroecologia, motivadas pelas críticas e injustiças promovidas desde a modernização agrícola. Essa formação envolveu um campo de oposições, em especial frente ao agronegócio ${ }^{4}$, propondo alternativas, bem como um conjunto de bandeiras e temáticas articuladas à agroecologia, enquanto uma proposta de vida em sociedade, em discursos consensuados entre seus integrantes (Melucci, 2001).

A categoria movimentos sociais contribuiu para refletir como ocorreu a criação e manutenção da ANA, na medida do possível decompondo seus elementos de ação coletiva, para entender como se formou esse "nós". O processo de avaliação e reconhecimento de identificação coletiva entre organizações se colocou desde o começo e também se refez em percepções interativas e negociadas das oportunidades e vínculos de ação. A unidade desse ator coletivo não é algo dado, mas resultado do intercâmbio, da negociação, das decisões e dos conflitos. Essa caminhada desencadeada em função de determinadas lutas sociais também incluiu tensões em relação a diferentes práticas, concepções e estruturas entre seus atores, e que sinalizaram os

\footnotetext{
${ }^{3}$ Aspecto também presente a partir da hermenêutica, como em Ricoeur, P. Interpretação e ideologias. Rio de Janeiro: F. Alves, 1988.

${ }^{4} \mathrm{O}$ termo agronegócio ao longo dos documentos da ANA tem um sentido político. A proposta agroecológica explicita as consequências para a sociedade e a natureza do domínio da modernização da agricultura pelas elites agrárias, enquanto formas de geração e acumulação de capital.
} 
contornos dos consensos, da proposta política e sobre como os atores lidaram com suas diferenças nestes processos de ação coletiva.

Ao percorrer a construção histórica da ANA percebemos que ela se configurou como uma rede social, ao mobilizar relações, recursos e significados, buscando a "interconexão entre diferentes mundos e formas de conhecimento, transcendendo domínios institucionais específicos e interligando uma grande diversidade de arenas" (Schmitt, 2011, p. 92). A estruturação de relações e vínculos construiu a própria articulação.

Ao longo da pesquisa, a abordagem relacional permitiu entender os atores em seus contextos de relações, influências, estrutura de vínculos, conflitos e alianças. A rede social foi tanto o produto de uma conjugação entre ação orientada a fins, acaso e herança dos padrões de vínculo anteriores, quanto também foi compreendida pelas ações dos atores, da sua intenção em formar, manter e influenciar essa rede social (Marques, 2006; 2007).

$\mathrm{O}$ aparecimento da agroecologia partiu da construção das alternativas à Revolução Verde ${ }^{5} \mathrm{e}$ a sua elaboração se relacionou com a construção de um frame, na medida em que formulou críticas, diagnósticos, procura de soluções e mobilização para a ação coletiva (Benford \& Snow, 2000). Ressignificou conhecimentos populares e científicos, dando sentido e significado cognitivo para uma ação política. A ANA, como um ator coletivo organizado em rede, atuou diretamente para produzir esses consensos, articular, manter e difundir este novo frame, ou seja, a busca da compreensão do frame como aquilo que anuncia, formula, negocia e constrói os contornos da agroecologia enquanto um problema público a ser reconhecido pela sociedade, tornando-se um dos seus porta-vozes. O problema público foi compreendido como parte do trabalho coletivo dos atores estudados para a identificação e reconhecimento da agroecologia, procurando transbordá-la para diversos espaços sociais de atenção pública e de ação prática (Cefaï, 2002).

Isso porque os movimentos sociais não apenas são portadores de ideias e significados, mas são agentes ativos na produção e manutenção de significados na sociedade para orientar e legitimar sua ação (Benford \& Snow, 2000). A agroecologia explicitou a construção dos frames enquanto uma ação processual e interativa que implica em agência e controvérsia pelos movimentos sociais, gerando interpretações e significados diferentes dos existentes, inclusive modificando-os.

A caminhada da agroecologia misturou novas e antigas questões desde a construção das tecnologias alternativas e das pautas pela reforma agrária, numa articulação de framings que conectaram eventos, experiências e códigos morais que se unificaram em determinados caminhos, formando uma nova linguagem. O resultado da agroecologia nessa perspectiva não seria a originalidade dos elementos ideológicos, mas captar a "maneira que eles são emendados e articulados, de tal modo que um novo

\footnotetext{
${ }^{5}$ A proposta da Revolução Verde teve início nos EUA e Europa, em especial depois da $1{ }^{\text {a }}$ Guerra Mundial, no objetivo de modernizar a agricultura, com apoio do Estado. No Brasil, está presente desde a década de 1960 com o objetivo de ampliar a produtividade com uso de agrotóxicos, sementes modificadas, mecanização e monocultivos em larga escala, para geração de excedentes pela exportação. Isso gerou, por exemplo, a perda e diminuição da biodiversidade, dependência do modelo produtivo junto das empresas fornecedoras e compradoras, geralmente multinacionais, processos de endividamento e perda de autonomia dos agricultores, morte e contaminação do meio ambiente. Tal processo também é colocado como "modernização conservadora", pois manteve e acentuou o quadro de concentração fundiária e econômica, e ainda, com forte carga ideológica quanto a inevitabilidade do modelo, atuando diretamente na formação agronômica. Para uma visualização mundial dos efeitos da Revolução Verde / modernização conservadora ver Molina (2009).
} 
ângulo de visão, interpretação e entendimento é fornecido" (Byrd \& Snow, 2010, p. 329). Buscamos entender essa base de apoio, os novos temas no discurso, valores e públicos desse problema público e as dinâmicas interativas na construção do frame agroecológico (Cefaï \& Trom, 2008), e como ocorreu a configuração desse quadro interpretativo agroecológico entre distintas organizações sociais (Tarrow, 2009) que explicam porque os atores se engajaram nessa ação coletiva.

Além disso, a relação dos movimentos sociais com o poder público é, se não central, constitutiva do seu surgimento e formulação. No caso da agroecologia essa interlocução foi permanente, reivindicando políticas públicas e o reconhecimento da agroecologia como objeto de ação do poder público. O confronto político encampado pela ANA travou-se no âmbito institucional em estratégias não violentas (Mcadam et al., 2009), ainda que questionada por alguns dos seus integrantes. E mais do que isso, a ANA orientou sua confrontação para a valorização do trabalho diário dos agricultores familiares agroecológicos, no sentido de uma resistência cotidiana (Scott, 2002).

\section{A emergência do movimento agroecológico}

$\mathrm{O}$ espraiamento da agroecologia retrata o processo de construção de frames, não apenas no sentido da sua formulação pelos movimentos sociais, mas das dinâmicas interativas dos atores e da busca pelo compartilhamento e recriação desses significados, ou dos seus denominadores comuns entre múltiplas organizações (Cefaï \& Trom, 2008). Isso porque, conforme visualizado,

\begin{abstract}
o potencial de convicção e mobilização de um movimento social depende de suas estratégias de agregação e de consenso, de suas táticas de inovação, de delimitação e de enfrentamento e também da capacidade dos poderes públicos de traduzir suas reinvindicações em dispositivos legais ou institucionalizá-las em políticas públicas, ou ainda, no equilíbrio entre os argumentos opostos e sua visibilidade para os meios massivos (Cefaï \& Trom, 2008, tradução nossa).
\end{abstract}

Retratando brevemente esse processo, a difusão da agroecologia foi antecedida pela construção da agricultura alternativa, em especial na década de 1980, impulsionada pela interação entre elementos diversos como: as lutas sociais pela redemocratização do país, a crise do sistema convencional de produção, com contaminação, endividamento e resistência dos agricultores, além do crescimento da preocupação ambiental na interação entre as escalas internacionais e locais ${ }^{6}$.

A formulação e explicitação das críticas à Revolução Verde partiram de intelectuais e agrônomos com uma maior expressão nos Encontros Brasileiros de Agricultura Alternativa (EBAAs) na década de 1980, enquanto espaço pioneiro de intercâmbio e contestação do modelo agrícola, em plena ditadura militar. Além disso, outro ator histórico nesse período foi o Projeto de Tecnologias Alternativas, ligado à Federação de Órgãos para a Assistência Social e Educacional (PTA/Fase) que promoveu a identificação, reconhecimento e articulação de experiências de agricultura alternativa em diversas regiões do país, protagonizada por militantes com conexões em redes internacionais e por agrônomos contratados pelo projeto.

\footnotetext{
${ }^{6}$ Por exemplo, os intercâmbios dos agrônomos com as questões internacionais e sua ação no âmbito local com agricultores ou os efeitos locais, a partir dos debates promovidos pela Organização das Nações Unidas (ONU).
} 
A agricultura alternativa permitiu uma identificação simbólica entre causas, consequências e levantamento de soluções à modernização da agricultura e, ainda que não se consolidasse como um ator coletivo, por uma série de clivagens durante os EBAAs, teve o inicial protagonismo desde as redes no interior da agronomia com uma crescente entrada e adesão de novos atores, articulando pautas e questões históricas, como a reforma agrária e procurando, no caso do PTA/Fase, a adesão de atores que pudessem ampliar o alcance da proposta, como os agricultores e as organizações dos movimentos sociais.

A noção de rede estava presente quando do projeto PTA/Fase: com seu desenvolvimento e expansão por equipes pelo país, reformulou sua atuação como Rede PTA, no objetivo de ampliar a proposta da agricultura alternativa e gerar maior autonomia para as dezenas de ONGs envolvidas. Depois, já no final dos anos 1990, a Rede PTA ainda verifica sua baixa capacidade de interferência no cenário nacional, numa atuação limitada às ONGs, desencadeando então a preparação e mobilização para um encontro nacional, na expectativa de maiores adesões ao problema público que encampava.

A incorporação da noção da agroecologia ocorre no final da década de 1980, nas interações da Rede PTA com atores latino-americanos, como o Consórcio Latino-Americano de Agroecologia e Desenvolvimento Sustentável (Clades), com a referência inicial do pesquisador e agrônomo Miguel Altieri, o que amplia o campo discursivo para a área científica, a dimensão cultural e ambiental, e se articula com os processos históricos das lutas no campo e da agricultura alternativa.

A agroecologia afirmou-se como referência conceitual principalmente desde a década de 1990, com o amadurecimento da análise ecológica da agricultura e da consciência ambiental, abarcando diferentes áreas do conhecimento como as ciências agrícolas, ecologia e o desenvolvimento rural. Incorporou, no caso do Brasil, pautas amplas e históricas dos movimentos sociais rurais, como reforma agrária, valorização do rural, da mulher e da biodiversidade, educação, construção de novos mercados e juventude. Ampliou os elementos técnicos e incorporou aspectos políticos e valorativos, seja na relação dos homens e mulheres entre si, seja dos seres humanos com a natureza e também no campo científico. E, nesse sentido, a agroecologia se coloca não só como um campo do conhecimento, mas também como outra forma de vida em sociedade e com a natureza.

No campo das organizações dos movimentos sociais, até a década de 1990, sua maior reivindicação era pela mera inclusão produtiva com apoio do Estado, apesar das críticas sobre a inadequação da modernização agrícola aos pequenos agricultores. A pauta da agroecologia nessas organizações aparece na maior parte nos anos 2000, fruto de interações, renovações discursivas, embate com o agronegócio, efeito dos agrotóxicos e das suas próprias experiências produtivas agroecológicas. Isso ocorreu principalmente na Confederação Nacional dos Trabalhadores da Agricultura (Contag), Federação Nacional dos Trabalhadores e Trabalhadoras na Agricultura Familiar (Fetraf) e Movimento dos Trabalhadores Rurais Sem Terra (MST), e seguiu por caminhos diferentes no Movimento dos Pequenos Agricultores (MPA) com lastro nas experiências anteriores dos outros movimentos, trazendo a agroecologia de modo mais fundante com sua criação em meados dos anos 1990. Nos movimentos de mulheres, a incorporação da agroecologia se articula com 
sua histórica pauta ambiental e pela autonomia das mulheres agricultoras. Essa absorção gerou um ciclo de reinvindicação dessas organizações junto da agroecologia e fortaleceu a coalizão e a identidade em torno dela (Mcadam et al., 2009).

O encontro e mobilização de atores distintos, como entre assessores, militantes e agricultores, potencializou um novo quadro de lutas desde a negação da modernização agrícola até os conflitos fundiários, ampliando as redes e a proposta política, o que contribuiu no processo de formação de uma vontade coletiva. A adesão à agroecologia foi fruto de reformulações de cada organização de movimento social, numa interação permanente e reflexiva. Isso envolveu reconhecer e recobrir na noção da agroecologia elementos científicos e técnicos de produção, viabilidade econômica para a agricultura, mudanças culturais e interação entre o saber popular e o cientifico (Figura 1). A formulação da agroecologia como problema público envolveu controvérsias e focos distintos por esses atores, e depois, na ressonância que a questão teve frente ao restante da sociedade, a partir de uma argumentação que procurou convencer públicos e solicitar seu engajamento (Cefaï \& Trom, 2008).

\subsection{Agroecologia como campo de pesquisa e conhecimento}

No campo científico, pesquisas sobre a agroecologia têm sido feitas principalmente pelas ciências agrárias, biológicas e da saúde, sendo inúmeras e crescentes as reflexões sobre experiências produtivas e estudos de caso, o que evidencia a grande importância do tema para essas ciências, em especial por meio da investigação de seus impactos e potencialidades diversas, em modos de produção,

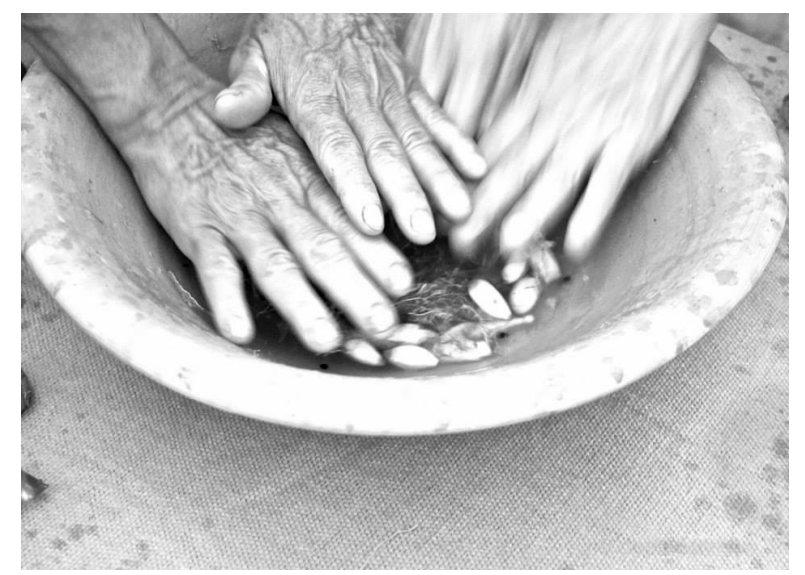

FIGURA 1 - Mãos e sementes simbolizando a agroecologia. FONTE: ANA.

geração de trabalho e manutenção das famílias e comunidades. Também se encontram estudos sobre aspectos participativos, educativos, de gênero, desenvolvimento rural, políticas públicas e sustentabilidade das práticas, bem como a inserção transdisciplinar e epistemológica da agroecologia.

Investigações de caráter local e com temas correlatos a agroecologia também revelam as diversas variáveis que influenciam a produtividade biológica e a eficiência econômica desses sistemas produtivos. Mas se há riqueza empírica, há também tendência a fragmentar ou a não analisar todos os componentes econômicos, sociais, políticos e ambientais, muitas vezes sem considerar o universo social e cultural dos agricultores, bem como a falta de critérios e análises sobre relações de poder e do conflito (Schmitt, 2009; Molina, 2009).

Isso reflete a forma como o tema se inseriu até então no meio acadêmico e a menor intensidade do olhar das Ciências Sociais, na perspectiva de investigar os múltiplos lugares, formas e momentos em que a agroecologia se transformou em um problema 
público (Cefaï, 2011), em uma mobilização coletiva, nos esforços para o bem viver, estratégias de resistência e as capacidades para inventar formas de participação e ação política, como se propôs a ANA.

Recentemente dois estudos abordaram a relação entre movimentos sociais e agroecologia, repercutindo essa importância de análise, mas ainda sem relacionar as relações de poder e as tensões internas desse campo. Dornelas (2016) estudou a construção do conhecimento agroecológico com a Ecologia de Saberes e a ruptura com as colonialidades do saber e do poder, incluindo também a ANA e o histórico da sua construção. Strauch (2015) investigou como as experiências agroecológicas em Paraty contribuíram para a estratégia de resistência do campesinato frente ao intenso processo de desterritorialização.

Outro termo utilizado tanto no meio acadêmico quanto nas práticas sociais é "transição agroecológica", atuando como referência de análise entre os múltiplos fatores e dimensões sociais envolvidos na transição para uma agricultura mais sustentável, por exemplo, no confronto entre visões de mundo, novas identidades, processos de conflito e negociação. Compreende-se essas iniciativas como construções sociais, por meio da interação entre atores, recursos, atividades e lugares nos processos de desenvolvimento rural, visto que nem todas as práticas se identificam ou representam uma unidade agroecológica, expressando diferentes níveis de complexidade e entendimento do campo agroecológico (Schmitt, 2009). Nesse sentido, os conceitos de transição agroecológica e de agroecologia estão em construção e em disputa.

Essa amplitude no plano científico e social da agroecologia, bem como a importância de delimitar sua ação pública e sua ancoragem nas instituições, remete à pluralidade de pontos de vista, com uma multiplicidade de atores e instituições que a utilizam. Na pesquisa, identificamos brevemente os lugares em que a agroecologia apareceu como objeto de trabalho político, tanto para o enquadramento da ação quanto como referência identitária, percebendo também seu diálogo com outros mundos sociais, além de considerar as controvérsias como parte da construção desse conhecimento (Billaud et al., 2015).

\subsection{A criação da Articulação Nacional de Agroecologia}

A então crescente difusão da noção da agroecologia na década de 1990 favoreceu a realização do I Encontro Nacional de Agroecologia em 2002, promovido inicialmente pela Rede PTA, que convocou diversas organizações de movimentos sociais e grupos acadêmicos já sensibilizados com a pauta, formando uma comissão organizadora ${ }^{7}$. Esse encontro iniciou o aprofundamento da dimensão política e não apenas técnica de produção agroecológica, em direção a propostas de desenvolvimento e mudança social, promovendo também a autoidentificação dos atores da agroecologia, como agricultores familiares, lideranças de movimentos sociais, pesquisadores, extensionistas e assessores. Realizou-se também um diagnóstico inicial sobre as condições e reivindicações sociais desses atores, procurando influenciar o contexto das eleições federais e estaduais da época.

A ANA é criada após o I ENA, composta pelas organizações da comissão organizadora desse primeiro encontro nacional. As primeiras atividades da ANA se iniciam em Grupos de Trabalho, em temas de interesse das organizações, como: construção do conhecimento e assistência técnica, conservação e biodiversidade, mulheres, financiamento da transição agroecológica e soberania e segurança alimentar. 
De forma mais propositiva do que até então a pauta da agroecologia indicava, a criação da ANA permitiu e buscou uma maior ação coletiva dos atores da agroecologia, cuja trajetória visitada mostra uma contínua construção sobre oportunidades políticas, a partir da leitura compartilhada de cenários a cada conjuntura política, no objetivo de mobilizar consensos e ações (Cefaï \& Trom, 2008).

Em 2006, também em um período eleitoral, realiza-se o II ENA, que aprofunda as iniciais questões que fundamentaram a coesão da ANA, partindo da oposição ao agronegócio, em uma crítica que permitiu a união dos atores e um jogo crescente de distinção (Bourdieu, 1990). Aquele momento também expressou a pressão e as expectativas sobre as políticas públicas para a ampliação da proposta agroecológica, dada a oportunidade de interferência e construção junto ao governo federal sob a gestão do Partido dos Trabalhadores (PT).

AANAdesde seu início expressou-se como formuladora de políticas com uma interface socioestatal, em relações com o Estado fora dos espaços formais entre Estado e sociedade civil (Almeida et al., 2014), o que não excluiu sua participação em conselhos e outros espaços de negociação direta com o governo. Essa relação incluiu as tensões entre autonomia e integração com o governo e, de outro lado, isso também favoreceu a articulação do campo agroecológico, o acesso às políticas públicas e uma maior capacidade de difusão da agroecologia enquanto problema público. Caminharam então numa cooperação conflituosa junto ao Estado (Chechi, 2017).
Na sua trajetória, a ANA inicialmente procurou ser um espaço de encontro e troca entre atores políticos, e foi de modo crescente se legitimando como ator político, com poder de coesão e ressonância no campo agroecológico, representando uma força política. Isso em especial a partir da sua maior interlocução com as políticas públicas e na mobilização dos ENAs, o que, de outro lado, pressionou internamente por ações mais diretas da própria ANA.

As organizações e coletivos que integravam a ANA em 2016 eram: Associação Brasileira de Agroecologia (ABA), Articulação do Semi-Árido Brasileiro (ASA Brasil), Conselho Nacional dos Seringueiros (CNS), Coletivo Nacional de Agricultura Urbana, CPT, Coordenação Nacional das Comunidades Quilombolas (Conaq), Contag, Feab, Fetraf, Fórum Cearense pela Vida no Semiárido, Unefab, MPA, Movimento de Mulheres Camponesas (MMC), MST, Movimento da Mulher Trabalhadora Rural do Nordeste (MMTR-NE), Movimento Interestadual de Quebradeiras de Coco Babaçu (MIQCB), Rede Cerrado, Rede de Mulheres Empreendedoras Rurais da Amazônia (Remera), Rede Ecovida, Rede de Grupos de Agroecologia do Brasil (Rega), União Nacional das Cooperativas da Agricultura Familiar e Economia Solidária (Unicafes) $^{8}$. Há ainda as redes estaduais e regionais de agroecologia, dentre as quais: Articulação de Agroecologia do Rio de Janeiro (Aarj), Articulação Mineira de Agroecologia (AMA), Articulação Paulista de Agroecologia (APA), Grupo de Intercâmbio em Agroecologia, (Gias) do Mato Grosso, Projeto

\footnotetext{
${ }^{7}$ ONGs: Assessoria e Serviços a Projetos em Agricultura Alternativa (AS-PTA), Centro Ecológico Ipê, Centro Sabiá, Centro de Tecnologias Alternativas da Zona da Mata (CTA-ZM), Fase, Grupo de Trabalho Amazônico (GTA), Grupo de Assessoria em Agroecologia na Amazônia (GTNA) e Serviço de Assessoria a Organizações Populares Rurais (Sasop); Movimentos sociais: Articulação Nacional de Mulheres Trabalhadoras Rurais (ANMTR), Conselho Nacional de Populações Extrativistas (CNS), Contag, Feab, Fetraf-Sul, MPA e MST; Redes: Articulação do Semiárido (ASA Brasil), Rede Cerrado e Rede Ecovida de Agroecologia; Grupos acadêmicos Grupo de Estudos sobre Reforma Agrária da Universidade Federal do Mato Grosso (Gera-UFMT) e União Nacional Escolas da Família Agrícola do Brasil (Unefab) e organização vinculada à Igreja Católica, a Comissão Pastoral da Terra (CPT).
} 
Terra sem Males, Rede ANA Amazônia, Rede Juçara, Rede Maniva de Agroecologia (Rema), no Amazonas e Rede Sergipana de Agroecologia (Resea). Essa diversidade de organizações expressa uma grande abrangência de articulação pelas regiões, contextos, identidades e biomas. Incluem-se também as diversas ONGs que atuam na ANA, como as que integram seu Núcleo Executivo: AS-PTA, CTA-ZM e Fase, que dentre outras ONGs, estão presentes desde a Rede PTA.

Além do Núcleo Executivo que operacionaliza, modera e acompanha as atividades da ANA, seus outros espaços são: Secretaria Executiva, organizando sua dinâmica cotidiana e seus projetos; os diversos Grupos de Trabalho formados por temas e pautas de interesse, além de sua Plenária Nacional, reunindo a diversidade de atores que compõe a ANA.

De modo mais recente, articulações de outros campos temáticos passaram a integrar suas reuniões nacionais, frente ao seu objetivo de novas adesões para o frame agroecológico, como a Articulação dos Povos e Organizações Indígenas (Apoinme), Associação Brasileira de Saúde Coletiva (Abrasco), Fórum Brasileiro de Economia Solidária (FBES), Fórum Brasileiro de Soberania e Segurança Alimentar e Nutricional (FBSSAN), Marcha Mundial de Mulheres (MMM) e Rede Brasileira de Justiça Ambiental (RBJA).

\subsection{Interfaces: confluências e divergências na Articulação Nacional de Agroecologia}

A partir do acesso e análise das reuniões nacionais da ANA, percebemos as relações entre atores da sociedade civil e destes com as políticas públicas, numa repetição argumentativa que procurou mobilizar consensos. AANA se mostrou como difusora da proposta agroecológica, selecionando novos aliados e temas que pudessem fortalecer seu objetivo, ampliando o alcance da rede social da agroecologia.

As reuniões mostraram um dos seus modos de ação e forma metodológica ao partir de análises e avaliações, a exemplo das conjunturas eleitorais, procurando influenciar as futuras gestões federais. As contradições percebidas junto aos governos federais forjaram o caminho para a interlocução com outras organizações da sociedade civil, como nos temas da saúde coletiva, mulheres, justiça ambiental e economia solidária, percebendo-se suas sobreposições e predisposições ao envolvimento com a agroecologia. Isso culmina na realização do Encontro Nacional de Diálogos e Convergências em 2011, promovendo traduções e inteligibilidades recíprocas entre diversas organizações, partindo da crítica ao modelo de desenvolvimento dominante (Santos, 2002). Isso reformula a construção agroecológica que, se antes ancorava sua oposição com o agronegócio, passa então a evidenciar o conflito de forma mais ampla com o modelo capitalista de desenvolvimento, o que facilitou a aproximação da ANA com novos atores e lutas sociais.

Percebemos a existência de ciclos de maior interlocução junto ao governo, como na abertura do governo para a construção da Política Nacional de Agroecologia e Produção Orgânica (Pnapo) desde 2012 e, de outro lado, no aprofundamento das interfaces com a sociedade civil, como na publicação do "Dossiê Abrasco: um alerta sobre os impactos dos agrotóxicos na saúde ${ }^{10 "}$. Esses ciclos não foram excludentes, mas relacionais entre as tensões

\footnotetext{
${ }^{8}$ Fonte: http://www.agroecologia.org.br/o-que-e-a-ana/. Acesso em 09.02.2016.

${ }^{9}$ Fonte: http://www.agroecologia.org.br/o-que-e-a-ana/. Acesso em 09.02.2016.
} 
sobre prioridades, resultados e condições de ação da ANA. Houve uma crescente percepção sobre o esgotamento do atendimento parcial das demandas provocadas para a agroecologia, frente ao apoio estatal com o fortalecimento do agronegócio e as dinâmicas de concentração de capital.

Isso também ocorreu no III ENA, em 2014, que aprofundou as formas, canais, público, linguagens e ferramentas da comunicação agroecológica (Figura 2), desde sua questão mobilizadora: "Por que interessa à sociedade apoiar a agroecologia?", e que contou com a presença de diversas redes, temas e organizações da sociedade civil no evento e na sua preparação. Assim como nos outros ENAs, os temas desses encontros procuraram influenciar as políticas públicas e a gestão da vida em sociedade, expressando os consensos em cartas políticas que se revestiram como um ato que institucionalizou e oficializou as afirmações públicas, contando também com a presença de representantes governamentais no evento.

O encontro de 2014 evidenciou de forma explícita o processo de identificação mútua e dramatúrgica da ação coletiva agroecológica, na marcação de um "nós" e um "eles", entre os públicos simpatizantes e oponentes da agroecologia, quando os problemas são convertidos em problemas públicos, em uma arena política e em processos de comunicação pública (Cefaï \& Trom, 2008). Isso se colocou não apenas para o âmbito externo, mas interno da própria agroecologia, o que fortalece a identidade do próprio movimento agroecológico.

Em todos os encontros nacionais, como os

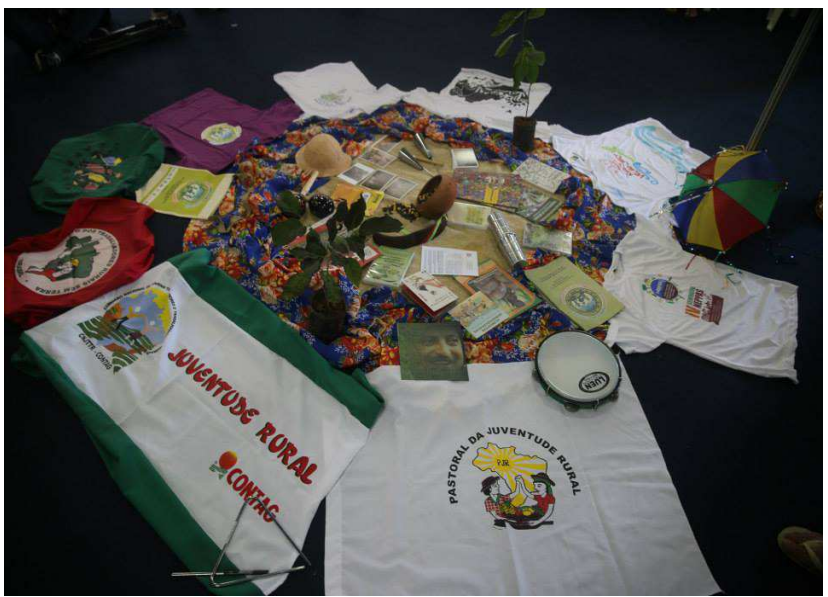

FIGURA 2 - Objetos utilizados como símbolos representativos no III ENA, Juazeiro, 2014.

FONTE: ANA.

ENAs, documentos e proposições da ANA, procurou-se evidenciar a agroecologia por meio das suas experiências e das práticas de seus protagonistas, agricultoras e agricultores familiares, que de modo crescente foram o principal público daqueles eventos. Buscaram então, num processo de mobilização e organização nacional, fornecer credibilidade empírica, congruência semântica e maior aderência na construção deste frame (Benford \& Snow, 2000; Cefaï \& Trom, 2008). Os ENAs também se constituíram como um repertório político (Mcadam et al., 2009), no sentido de ligar reivindicadores com os objetos de reinvindicação, ao ser um momento de encontro desses atores e de ações públicas ali realizadas, como a feira de trocas de sementes e em 2014 com marchas e ocupações públicas (Figura 3).

Os documentos acessados da ANA expressaram o esforço do consenso e das posições coletivas,

\footnotetext{
${ }^{10}$ Dossiê disponível em: http://abrasco.org.br/dossieagrotoxicos/. Foram lançadas quatro partes do dossiê, a primeira relacionada ao tema da saúde, buscando focar nas causas dos problemas e priorizar a implantação do Pnapo. A segunda com o tema do meio ambiente, a terceira sobre o conhecimento popular, construindo uma ecologia de saberes. E a quarta sobre a agroecologia. O dossiê também foi impulsionado com a Campanha Contra os Agrotóxicos e pela vida, uma estratégia de trazer pessoas do campo e da cidade para o debate, mobilizando também o campo da ciência (Articulação Nacional de Agroecologia, 2012).
} 
construindo para fora sua visão como ator coletivo. Buscaram na ciência, na comunicação e na mídia formas que legitimassem os seus discursos e interpretações de mundo, de forma que promovesse o reconhecimento público da agroecologia.

A partir das entrevistas abordamos com mais atenção os dilemas e confrontos existentes na articulação, dentre diferentes concepções, estratégias de ação, relações de poder e as interfaces na rede da ANA. As entrevistas mostraram posições dissonantes e as heterogeneidades, refletindo as posições sociais e institucionais, como das ONGs e das organizações dos movimentos sociais. Para a compreensão desses discursos nas suas referências político-ideológicas e na capacidade de ação política, verificamos diversas matrizes discursivas dos atores, como: religiosa (como a referência da Teologia da Libertação), racionalidade produtiva, marxista, sindicalista e científica. Matrizes estas que também se relacionam e se entrelaçam.

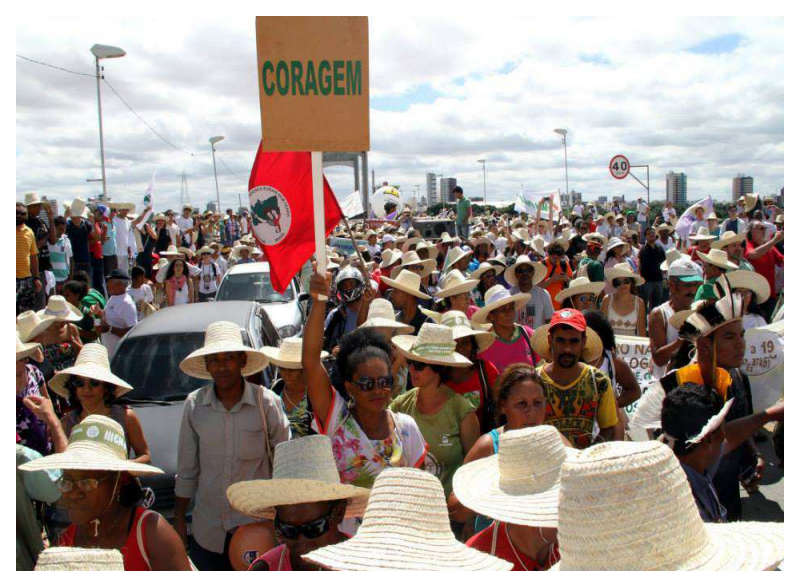

FIGURA 3 - Marcha no III Encontro Nacional de Agroecologia, Juazeiro, 2014.

FONTE: ANA.
As concepções de agroecologia expressadas pelos atores entrevistados mostraram vários ângulos de atuação, entre escalas e expectativas pessoais, culturais, econômicas e políticas, que remetem a existência de várias agroecologias, no seu plural. Numa tentativa de sistematização, foram percebidos sete ângulos da proposta agroecológica, não necessariamente excludentes entre si, como: 1) a perspectiva de ação com maior escala e confrontação violenta, inserida na formação de uma classe ou movimento social; 2) valorização do acesso aos mercados com produtos de maior valor agregado; 3) cultura e valor de resistência das experiências; 4) ação política que se contrapõe ao agronegócio, busca a autonomia dos agricultores e o fim da opressão contra a mulher; 5) formação de redes sociais e econômicas para sobrevivência e manutenção dos agricultores; 6) perspectiva científica e tecnológica da agroecologia para a mudança no padrão da produção alimentar e na dinâmica de redes de produção do conhecimento; e ainda, 7) estilo de vida e uma utopia. Essas perspectivas são então colocadas em contato na ANA, entre mundos diversos.

Outro elemento visualizado foi que a tênue articulação entre os atores na ANA se explicitou na ausência de mecanismos próprios de ação e de vinculação entre as organizações e as escalas, com fluidos e heterogêneos envolvimentos. As conexões mais fortes ocorreram entre as ONGs que historicamente promoveram a pauta agroecológica, desde a Rede PTA. A abstração em torno da organização em rede explicitou, entre os atores entrevistados, expectativas sobre a necessidade da sua pactuação em objetivos compreendidos pelas suas partes e na efetividade dos discursos. Quanto maior a extensão comunicativa ou o alcance pretendido por esse ator 
coletivo, possivelmente maiores as dificuldades em entender, enxergá-lo e se sentir parte dele.

A análise de redes não remeteu apenas a expectativa de horizontalidade, mas envolveu diferenças no acesso a informações, recursos, circulação, linguagem e poder político, ou seja, ao perceber seus graus de segmentação, centralização e dispersão, bem como relações de mediação entre redes de pessoas e organizações (Cefaï, 2011). Isso se materializa em tensões entre posições sociais de técnicos e agricultores e de ONGs e organizações de movimentos sociais. A especialização política das ONGs com a proposição e acolhimento da ANA gerou seu maior atrelamento na articulação: os atores não se dedicaram da mesma forma, nem com as mesmas condições. Isso, por sua vez, também expressou tensões entre representação e legitimidade no interior da ANA.

De outro lado, ao longo da trajetória vista, sua existência foi condicionada a objetos articuladores e problemas que animassem as interações e relações entre os atores (como os ENAs, campanhas como contra os agrotóxicos e pela vida e a construção da Pnapo), o que também expressou questões sobre como seria sua operação em rede, frente à pressão por resultados. Isso evidenciou dilemas sobre sua forma de ação, se numa posição mais negociada, como foi o que demonstrou, versus a ação direta de modo conflitivo contra o agronegócio ou na ação direta na parte produtiva e econômica em experiências agroecológicas. Essas diferenças expressaram as fronteiras entre as mudanças sociais defendidas pelos diferentes atores e as tensões quando numa dinâmica que se pretende diferente dos moldes hierárquicos tradicionais. Tais tensões não geraram rupturas, ainda que com envolvimentos e engajamentos distintos, e permitiram o diálogo, o reconhecimento e a troca, como exemplo dos seminários nacionais (Figura 4).

A relação com o Estado influenciou sua trajetória e atuação, como visto na oportunidade de construir políticas públicas nas gestões do PT no I ENA em 2002 e nos ENAs seguintes. Buscou ser uma interlocutora legítima com as políticas públicas, percebendo também os riscos no atrelamento excessivo com seus tempos e pautas, mas impulsionada pelo próprio reconhecimento da agroecologia como objeto de política pública. Utilizou então a estratégia de oportunismo político (Offe, 1984), com ganhos em curto prazo frente à assimetria de poder na relação com as políticas públicas e o agronegócio, refletindo a pressão frente à adesão nesse jogo político.

Se de um lado, a ANA se desenvolveu dentro de limites colocados por estruturas prevalecentes de oportunidade política, de outro, também alterou as estruturas de oportunidade, em especial ao consolidar uma identidade política em torno da agroecologia (Mcadam et al., 2009). Nesse sentido, o confronto

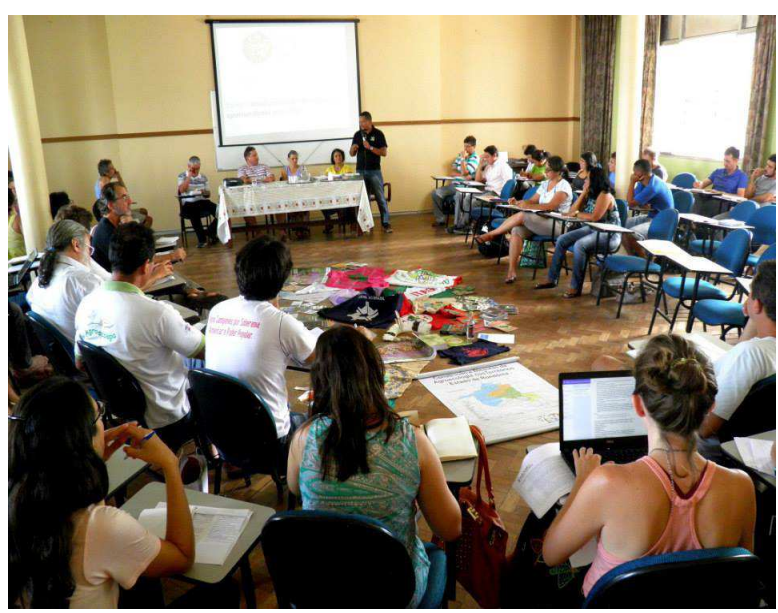

FIGURA 4 - II Seminário Nacional da ANA, Rio de Janeiro, fevereiro, 2015.

FONTE: ANA. 
político colocado pela ANA seguiu, de acordo com Tarrow (2009), uma reação às mudanças nas oportunidades e restrições políticas, recorrendo a ações baseadas em densas redes sociais e estruturas conectivas frente aos opositores do agronegócio, o que encorajou novos adeptos ao movimento agroecológico, como visualizado nos encontros nacionais de 2011 e 2014.

\section{Considerações finais}

A construção do campo agroecológico partiu de uma mudança molecular nas redes da agronomia e seguiu sua difusão para outros campos sociais. Percebemos os elementos, vínculos e atores nas relações dessa rede social, que buscaram construir, a partir de uma prática cognitiva, uma vontade coletiva (Cefaï \& Trom, 2008). A construção desse movimento social não partiu de um interesse localizado, mas formou-se no interior de uma rede de laços interpessoais que foi ganhando novos públicos e conexões (Mcadam et al., 2009).

A abordagem dos movimentos sociais permitiu perceber que a construção desse ator coletivo que não foi homogêneo, expressando ambiguidades e heterogeneidades, teve o agronegócio como seu principal opositor anunciado, na construção de um campo de conflitividade; aproveitou as oportunidades políticas e interfaces para aumentar seu poder político, a exemplo da construção de políticas públicas e da vinculação com as organizações ligadas à saúde coletiva, economia solidária, justiça ambiental, feminismo e soberania e segurança alimentar.

A ANA se colocou como formuladora e difusora da agroecologia, sem expressar descontinuidades entre os movimentos sociais e a política institucional, apontando escolhas estratégicas frente aos seus recursos, oportunidades e restrições (Mcadam et al., 2009). Articulou elementos de justiça, moralidade e respeito às diversidades sociais. A cada nova interface, a agroecologia foi se ressignificando com o alcance de novos públicos e adesões identitárias, procurando pontes semânticas com traduções negociadas, expressando-se como uma rede de influência, modificando e ajustando seu frame de ação coletiva de acordo com o público alvo (Benford \& Snow, 2000). A pluralidade de interpretações da agroecologia não importou tanto quanto os arranjos políticos permitidos por essa bandeira política, alargando demandas sociais históricas por mudança social e permitindo a coesão na ANA, nos termos de uma influência política conjunta (Tarrow, 2005).

A noção de agroecologia foi o principal elemento de coesão entre atores diversos, sendo que a própria ANA atuou diretamente nessa elaboração. Esse sentido construiu uma proposta de desenvolvimento, recobrindo vários temas sociais, não restritos aos aspectos produtivos. Buscou assim externalizar o frame da agroecologia como um problema público, utilizando mediadores como as representações políticas participantes da articulação, pela criação de meios próprios de comunicação e na realização de eventos nacionais, como os ENAs. Mesmo sem se colocar como um termo ambíguo, percebemos os múltiplos significados e controvérsias da agroecologia para os atores entrevistados, o que contribuiu para criar uma unidade provisória entre movimentos heterogêneos em processos de mobilização e alianças de um campo multiorganizacional (Mische, 2002).

Essa construção expressou a agroecologia como um frame: partindo do diagnóstico e da identificação do problema, a partir das consequências da modernização agrícola e depois com o agronegócio; criou prognósticos que levantaram reivindicações 
e possíveis alternativas a exemplo da agricultura alternativa, com a atração de novos atores, como as redes e organizações de movimentos sociais, o campo acadêmico e as políticas públicas e, então, procurou operadores para a ação coletiva, traduzindo pontes dialógicas entre universos sociais que motivassem à adesão a agroecologia, num processo dinâmico dessa elaboração. Os diversos elementos do contexto sociocultural interferiram neste framing processes, seja por constrangê-lo como o avanço da pauta do agronegócio com o apoio estatal, seja por facilitá-lo, como a oportunidade com a construção da Pnapo, a interferência nos períodos eleitorais e a maior ressonância das preocupações com a saúde e o meio ambiente na sociedade (Benford \& Snow, 2000).

Neste sentido, "os costumes e a revolta são tecidas a partir de uma mistura de fibras herdadas e inventadas nos frames de ação coletiva em confrontação com oponentes e elites" (Tarrow, 2009, p. 118). De outro lado, a elasticidade e o amplo escopo dado ao frame agroecológico podem enfraquecer sua proposta e significado, ou mesmo banalizá-lo, recobrindo extensas exigências dos atores no seu processo de contestação e pelas disputas e desagregações internas que lhes são características. Também porque as pontes geradas entre os atores que então se integraram à ANA, dada a congruência com a agroecologia, envolveram universos distintos, inclusive com perspectivas políticas em tensão, mas que não causaram paralisações na sua capacidade de ação coletiva, ainda que com diferentes e fluidos envolvimentos na ANA. Ao mesmo tempo, essa experiência pode se aproximar da construção de um master frame (Benford \& Snow, 2000) por ser genérico e flexível, acionado em diferentes situações e objetivos, buscando lograr ressonância no meio so- cial ao ser conectado com determinadas conjunturas e atores políticos.

A atração de novos adeptos e temas que incorporaram a pauta agroecológica ocorreu explicitamente em algumas interfaces, por exemplo, se na agricultura alternativa denunciava-se as contaminações do modelo agroquímico, com a agroecologia essa denúncia passou a ser articulada com um discurso qualificado cientificamente junto a instituições de pesquisa nacionais, como Universidades, Fundação Oswaldo Cruz (Fiocruz) e o Instituto Nacional de Câncer José Alencar Gomes da Silva (INCA) que comprovaram tecnológica e cientificamente as mortes e contaminações com o uso dos agrotóxicos. Da mesma forma, a busca pela articulação com os movimentos sociais rurais que trazem a pauta pela reforma agrária fortaleceu a agroecologia, em especial na sua disputa pelos territórios e nos desafios para sua ampliação produtiva, dado o restrito acesso e permanência territorial da agricultura familiar e dos povos e comunidades tradicionais pelo país. Nos movimentos de mulheres a agroecologia já era presente nas práticas das agricultoras que inseriram de forma irredutível as questões sobre violência contra mulher e a equidade de gênero no campo agroecológico.

A perspectiva interacionista do frame agroecológico foi evidente também nas mobilizações pelas políticas públicas, quando a pressão pela pauta foi acionada com maior ânimo nos períodos pré e pós-eleitorais, permitindo uma maior densidade política e social para a construção de um Brasil Agroecológico. Ou ainda, nos momentos de crise e questionamento do sistema social, a exemplo das contestações mundiais em 2011 e do crime na Bacia do Rio Doce em 2015, que para além das denúncias das situações, a agroecologia foi reafirmada como alternativa de desenvolvimento. 
Toda essa mobilização coletiva dos atores públicos teve diversas consequências pragmáticas, para além de constituir o movimento social agroecológico, dentre elas a construção de políticas públicas de agroecologia, a exemplo dos processos da Pnapo e dos Planos Nacional de Agroecologia e Produção Orgânica (Planapo) em dois períodos (2013-2015 e 2016-2019), e ainda, ao politizar diversas dimensões da vida individual e coletiva e estabelecer um novo campo para a ciência e a tecnologia no âmbito do sistema alimentar e na produção de conhecimentos. Seguindo Cefaï (2011), a ANA remodelou os campos de experiências ao promover inovações institucionais, lançando a agroecologia como um novo problema público e buscando sua efetivação em dispositivos de ação pública.

Na recente conjuntura de ruptura do processo democrático e ataques aos direitos sociais, com as tensões de um aprofundamento da agenda neoliberal, abre-se outro momento político para os atores da ANA, as quais podem ou não potencializar a confluência política entre as suas organizações e pressionar por práticas democráticas e participativas, ou ainda, frente ao recuo de oportunidades políticas no âmbito institucional, o que pode novamente modificar a construção deste frame agroecológico.

Por fim, nesta experiência, a agroecologia se configurou como mito, aproximando-se dos efeitos sociais de uma utopia e de um sonho politicamente mobilizador, frente aos conflitos e interesses que se revestem do termo. Saída da realidade social, recria-se com ela, formando uma nova utopia (Girardet, 1987).

\section{Agradecimentos}

Ao CPDA, em especial a orientação de Leonilde Servolo de Medeiros, e ao apoio do CNPq e da Faperj por meio da bolsa de pesquisa.

\section{Referências}

Almeida, L. S.; Comerford, J.; Palmeira, M. O mundo da participação e os movimentos sociais rurais: entre mobilizações, espaços de interlocução e gabinetes. In: Heredia, B.; M.; Lopes, J. S. L. (Orgs.). Movimentos sociais e esfera pública: o mundo da participação: burocracias, confrontos, aprendizados inesperados. Rio de Janeiro: CBAE, 2014, p. 67-88.

Articulação Nacional de Agroecologia. Seminário Nacional Convocatório ao III ENA. Luziânia-GO, 11 a 13 de dezembro de 2012.

Benford, R.; Snow, D. Framing Processes and Social Movements: an overview and assessment. Annual Review of Sociology, 26, 611-639, 2000.

Bensadon, L. S. Tecendo projetos políticos: a trajetória da Articulação Nacional de Agroecologia, Brasil. Rio de Janeiro, Dissertação (Mestrado em Ciências Sociais) - CPDA/ UFRRJ, 2016.

Billaud, J.; Brandenburg, A.; Lamine, C. A agricultura ecológica e as redes agroecológicas. In: Billaud, J.; Brandenburg, A.; Lamine, C. (Orgs.). Redes de agroecologias: experiências no Brasil e na França. Curitiba: Kairós ed. 2015, p. 7-15.

Bourdieu, P. A representação política: elementos para uma teoria do campo político. In: Bourdieu, P. O Poder Simbólico. Rio de Janeiro. Diffel, 1990, cap. VII.

Byrd, S. C.; Snow, D. A. Ideology, framing processess, and Islamic Terrorist Movements. Reading on Social Movements: origins, dynamics and outcomes. New York, Oxford, Oxford University Press, $2^{\mathrm{a}}$ ed, 2010.

Cefaï, D. Qué es una arena pública? Algunas pautas para un acercamiento pragmático. In: Cefaï, D.; Joseph, I. La herencia del pragmatismo. Conflitos de urbanidad y pruebas de civis- 
mo. La Tour d'Aigues, Editions de l'Aube, 2002, p. 51-81.

Cefaï, D. Diez propuestas para el estudio de las movilizaciones colectivas. De la experiencia al compromiso. Revista de Sociologia, 26, 2011.

Cefaï, D.; Trom, D. Los marcos de la acción colectiva. Definiciones y problemas. In: Natalucci, A. (Ed.). Sujetos, movimientos y memorias. Sobre los relatos del pasado y los modos de confrontación contemporâneos. La Plata, Al Margen, 2008.

Chechi, A. L. AArticulação Nacional de Agroecologia (ANA) e a construção da PNAPO e Planapos: um estudo sobre a relação de movimentos e organizações sociais e Estado. In: $9^{\circ}$ Congresso Latinoamericano de Ciência Política. Associação Latino-americana de Ciência Politica (ALACIP). Montevideu, 26 a 28 de julho de 2017.

Della Porta, D.; Diani, M. Social Movements: an introduction. Second edition. USA: Blackwell Publising. 2006.

Dornelas, R. S. Movimento agroecológico no Brasil: considerações sobre a dimensão política e os saberes na agroecologia. Brasil. Vitória, Dissertação (Mestrado em Ciências Sociais) - UFES, 2016.

Fraser, N. Reconhecimento sem ética? Lua Nova, 70, 2007.

Geertz, C. Uma descrição densa: por uma teoria interpretativa da cultura. In: Geertz, C. A interpretação das culturas. Rio de Janeiro: LTC, 1989, p. 13-41.

Girardet, R. Mitos e Mitologias Políticas. São Paulo: Companhia das Letras, 1987.

Honneth, A. Luta por reconhecimento: a gramática moral dos conflitos sociais. São Paulo: Editora 34, 2003, p. 253-268.

Marques, E. Redes sociais e poder no Estado brasileiro: aprendizados a partir das políticas urbanas. Revista Brasileira de Ciências Sociais, 21(60), 15-41, 2006.

Marques, E. C. Os mecanismos relacionais. Revista Brasileira de Ciências Sociais, 22(64), 157-161, 2007.

Mcadam, D.; Tarrow, S.; Tilly, C. Para mapear o confronto político. Lua Nova, 76, 2009.

Melucci, A. A invenção do presente. Petrópolis: Vozes, 2001.

Mische, A. Cross-talk in movements: reconceiving the cul- ture-network link. In: Diani, M.; Mcadam, D. (Eds.). Social Movement Analysis: The network perspective. Oxford University Press, 2002.

Molina, M. G. de. Las experiencias agroecológicas y su incidencia en el desarrollo rural sostenible. La necesidad de una agroecológica política. In: Sauer, S.; Balestro, M. V. (Orgs.). Agroecologia e os desafios da transição agroecológica. São Paulo: Expressão Popular, 2009.

Offe, C. Duas lógicas da ação coletiva: notas teóricas sobre a classe social e a forma de representação. In: Offe, C. Problemas estruturais do Estado capitalista. Rio de Janeiro. Tempo Brasileiro, 1984.

Offerlé, M. Sociologie des groupes d'intérêt. Paris, Montchrestien, 1998.

Olson, M. The logic of collective action. Cambridge: Harvard University Press, 1965.

Santos, B. de S. Para uma sociologia das ausências e das emergências. Revista Crítica de Ciências Sociais, 63, 237280, 2002.

Scherer-Warren, I. Redes de movimentos sociais na América Latina - caminhos para uma política emancipatória? Cadernos CRH, 21(54), 2008.

Schmitt. C. J. Transição agroecológica e desenvolvimento rural: um olhar a partir da experiência brasileira. In: Sauer, S; Balestro, M. Agroecologia e os desafios da transição agroecológica. São Paulo: Expressão Popular, 2009.

Schmitt. C. J. Redes, atores e desenvolvimento rural: perspectivas na construção de uma abordagem relacional. Sociologias, 13(27), 82-112, 2011.

Scott, J. Formas cotidianas da resistência camponesa. Raizes, 21(1), 2002.

Strauch, G. F. E. Redes sociotécnicas camponesas: inovações agroecológicas, autonomia, e articulação territorial em Paraty, estado do Rio de Janeiro. Espanha. Córdoba, Tese (Doutorado em Recursos Naturais e Sustentabilidade) - Universidade de Córdoba, 2015.

Tarrow, S. The new transnational activism. Cambridge: Cambridge University Press, 2005.

Tarrow, S. Poder em movimento: movimentos sociais e con- 
fronto político. Petrópolis, Vozes, 2009.

Thompson, E. P. Costumes em comum. Estudos sobre a cultura popular tradicional. São Paulo. Companhia das Letras, 1998.

Tilly, C. From mobilization to revolution. New York: McGraw-Hill, 1978.

Touraine, A. Na fronteira dos movimentos sociais. Sociedade e Estado, 21(1), 2006. 